\title{
Acquisition and extinction in the runway as a joint function of constant reward magnitude and constant reward delay
}

\author{
PETER HABLEY $\dagger$, MARTIN GIPSON $\dagger \dagger$, and JANET HAUSE $\dagger \dagger \dagger$ \\ University of the Pacific, Stockton, Calif. 95204
}

Three levels of constant reward magnitude and three levels of constant delay of reward were combined in a factorial design to determine the joint effects of reward magnitude and delay upon a runway response in rats. In acquisition, magnitude affected rate of learning and delay affected asymptotic level of performance, and the two variables interacted to affect both rate and asymptote. In extinction, magnitude tended to affect resistance to extinction while delay did not, and there was no interaction of the variables. Results were interpreted in terms of Capaldi's (1967) sequential theory.

Little research has been done on the ways in which constant magnitude of reward and constant delay of reward may combine to affect acquisition and extinction in simple learning situations. Logan (1960) reports a runway study in which reward magnitude was a within-Ss variable and reward delay a between-Ss variable, and concluded that the two combine additively in acquisition. Wist (1962) reports no significant Delay by Magnitude interaction in acquisition in a runway study where the delay conditions were not introduced until asymptotic performance levels were reached. More recent research has concentrated on partial delay effects (e.g., Campbell \& Wells, 1970; Capaldi, Godbout, \& Downs, 1968; Sgro, Moore, \& Showalter, 1970) and thus has not borne directly on the question. This study combined constant magnitude of and constant delay of reward, both as between-Ss variables, in a factorial design and examined their effects over both acquisition and extinction trials.

\section{SUBJECTS}

The Ss were 45 experimentally naive female albino rats of the Sprague-Dawley strain from Simonsen Laboratories (Gilroy, Calif.), 90-100 days of age at the beginning of prehandling. They were assigned on a random basis to a reward magnitude group of 2,4 , or 1245 -mg Noyes food pellets and to a reward delay group of 0,4 , or $8 \mathrm{sec}$. This resulted in a 3 by 3 factorial design containing $5 \mathrm{Ss}$ in each cell.

*This article is based in part on an MA thesis by the first author. The authors are indebted to Anna Kusick for her assistance in the data analysis.

+ Now at Ross Laboratories, Columbus, Ohio.

t+R equests for reprints should be sent to Martin T. Gipson, Psychology Department, University of the Pacific, Stockton, Calif. 95204.

+++ Now at Drake University, Des Moines, Iowa 50311 .

\section{APPARATUS}

The apparatus was a straight alley runway, $11.5 \mathrm{~cm}$ deep and $13 \mathrm{~cm}$ wide throughout. The startbox (SB) and goalbox (GB) were each $30.5 \mathrm{~cm}$ long and had pressed hardboard backs and floors and Plexiglas fronts and tops. The runway $(R)$ was $91 \mathrm{~cm}$ long with a pressed hardboard back and floor and a Plexiglas top and front. Identical pressed hardboard guillotine doors separated the SB from the runway, the runway from the $G B$, and the food compartment (FC) from the GB. The FC took up the final $3 \mathrm{~cm}$ of the GB.

Cramer clocks $(.01 \mathrm{sec})$ were used to measure the running times in three separate segments of the runway. The times recorded were: SB time, from the opening of the SB door to a first photocell $10 \mathrm{~cm}$ down the $R ; R$ time, from the first photocell to a second, $63.5 \mathrm{~cm}$ down the $\mathrm{R}$; and $\mathrm{GB}$ time, from this second photocell to a third, $13 \mathrm{~cm}$ into the GB.

\section{Prehandling}

Twenty-four hours prior to Day 1 of prehandling, all food was removed from the Ss' cages. On Days 1-7, each $S$ was allowed to run freely for $3 \mathrm{~min}$ in an open-field box. During the 3-min period, the $S$ was picked up every $15 \mathrm{sec}$, held for $5 \mathrm{sec}$, then placed in the middle of the box. Five $45-\mathrm{mg}$ Noyes pellets were placed in a food dish in the middle of the box at the beginning of each $3-\mathrm{min}$ period; pellets the $S$ failed to eat were returned with it to the home cage. A daily ration of powdered rat chow was administered 30 to $45 \mathrm{~min}$ following each S's prehandling. Ration size was varied to maintain each $\mathrm{S}$ at $90 \%$ of its ad lib weight.

\section{Acquisition}

Acquisition began $24 \mathrm{~h}$ after prehandling was terminated, and Ss were run one trial per day. On each trial, the $S$ was placed in the SB, the GB door opened, and the SB door opened when the $S$ oriented to it.
Following S's exit from the SB, the door was closed to prevent retracing, and following the $S$ 's entrance into the GB, the GB door was closed. Depending on the $S$ 's experimental condition, the FC door was opened at the same time as the GB door $(0-\mathrm{sec}$ delay condition) or at 4 or $8 \mathrm{sec}$ after the GB door was closed (4- and 8-sec delay conditions). All door operation was accomplished manually, with the delay period timed by a stopwatch. The Ss were allowed to eat all of the Noyes pellets before being returned to the home cage. Total GB confinement then consisted of the delay interval and the time taken in eating the pellets.

Acquisition was terminated for all Ss on Trial 41, when inspection of the average running speeds of each of the nine groups for the total SB-GB interval indicated all had reached an asymptotic level of performance.

Six Ss that failed to leave the SB within $2 \mathrm{~min}$ following $\mathrm{SB}$ door opening for five consecutive trials were discarded. Two of these were 2-pellet 0 -sec delay $\mathrm{Ss}$, and one each were 4-pellet 4-sec, 4-pellet 8-sec, 12-pellet 0 -sec, and 12-pellet 8-sec Ss. Replacements were made for all six from the original shipment of animals. Extinction

During extinction, all conditions remained identical to acquisition conditions except for the absence of food pellets in the FC.

The criterion for extinction was three consecutive failures to enter the GB within 30 sec or 30 trials. Each S was discarded upon reaching criterion. Of the nine $S s$ discarded before reaching 30 trials, three were from the 12-pellet 0 -sec group, two were from the 2-pellet 0 -sec group, and one each was from the 4-pellet 0 -sec, 2-pellet 4-sec, 12-pellet 4-sec, and 4-pellet 8 -sec groups.

Latencies for each of the three runway sections were summed to obtain a total runway latency, the totals were converted to reciprocals, and an analysis of variance was performed upon these total running speeds in both acquisition and extinction. Total running speed was the unit of analysis because, being the resultant of three separate latencies that intercorrelate to some degree in approach conditioning, it is the most reliable score obtainable from the apparatus (e.g., Nunnally, 1967, Chap. 6). Each analysis of variance involved the magnitude and delay variables and a trial variable.

\section{Acquisition}

Results in the form of mean running speeds are summarized in Fig. 1. The analysis of variance on these results yielded significant main effects for 


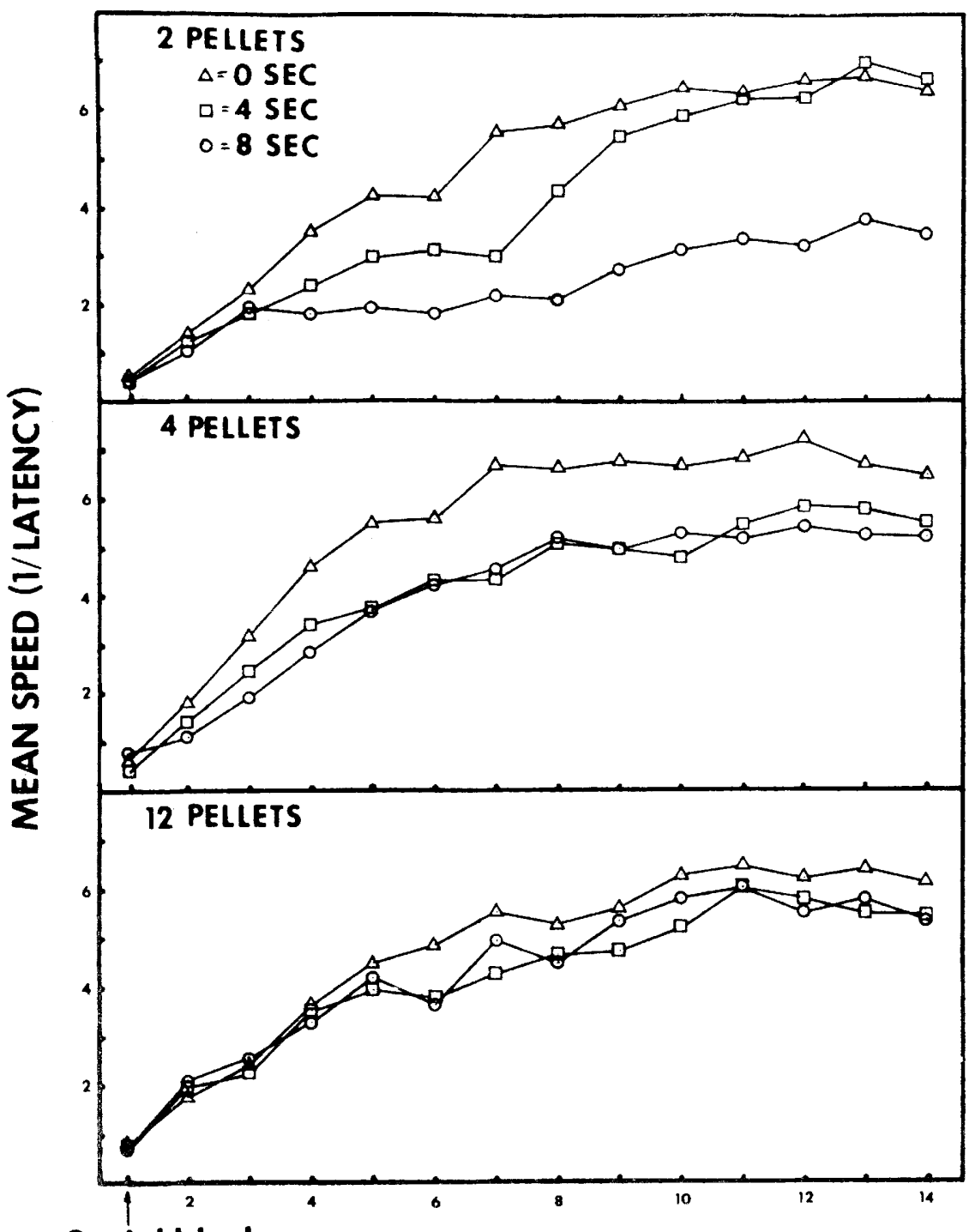

2 trial block

Fig. 1. Mean total running speeds in three-trial blocks for acquisition.

magnitude of reward $[F(2,36)=3.3$, $\mathrm{p}<.05]$, delay of reward $[\mathrm{F}(2,36)=$ $10.86, \quad p<.01]$, and trials $[F(40,1440)=71.06, p<.01]$. Since the means for the 4- and 12-pellet groups summed across trials were equal to two decimal places, the magnitude of reward main effect indicated that the 2-pellet group ran significantly more slowly than these groups. Examination of the delay main effect indicated that the 0 -sec delay group was significantly faster than both the 4- and 8-sec delay groups ( $p<.05$, Tukey's HSD).

A significant Delay by Magnitude interaction was found $[\mathrm{F}(4,36)=2.91$, $\mathrm{p}<.05]$. A test of the simple main effects indicated a significant effect of reward magnitude at 8 -sec delay $[\mathrm{F}(2,36)=10.96, \mathrm{p}<.01]$, but not at 0 - and 4-sec, and also revealed significant effects of delay at 2-pellet
Delay by Trials $[F(80,1440)=1.47$, $p<.01]$, but not for Magnitude by Trials or the triple interaction.

To separate the effects on asymptotic running speed of magnitude and delay from their effects on learning rate, an analysis of variance was performed upon asymptotic performance as estimated for each $S$ from the last 10 trials of acquisition. The magnitude main effect was not significant, while the delay effect was $[F(2,36)=11.00$, $p<.01]$. Since the effect of magnitude over all trials was significant, the analysis indicates this effect may be upon learning rate, or rate of reaching asymptote, and not on the asymptote itself. Delay, however, clearly affected asymptotic level of performance, with longer delays leading to lower asymptotic levels.

The asymptotic performance analysis also revealed a significant Magnitude by Delay interaction $[F(4,36)=4.00, p<.01]$. According to simple main effects and multiple comparison analyses, this is due to significantly slower running of the 2-pellet group at 8 -sec delay when compared with both the 4- and 12-pellet groups $(\mathrm{p}<.05$, Tukey's HSD) and to significantly slower running of the 8-sec delay group at 2 pellets when compared with the faster but equal performances of the 0 - and 4 -sec groups. This analysis parallels the interaction obtained with the analysis over all trials, except for the failure to find a significant simple effect for delay at 4-pellet reward. Thus, there is an indication that the interaction is due to asymptotic differences among the groups, except in the case of the delay effect at the 4-pellet reward level.

\section{Extinction}

The running speeds during extinction are summarized in Fig. 2. The analysis of variance on these data indicated significant main effects for delay of reward $[\mathrm{F}(2,36)=3.40$, $\mathrm{p}<.05]$ and trials $[\mathrm{F}(29,1044)=$ $48.00, p<.01]$, but the effect of reward magnitude just approached significance $[F(2,36)=3.20$, critical value $=3.26, \mathrm{p}<.05]$. The interaction was not significant $(\mathrm{F}=1.97)$. Examination of the delay means indicates the 8-sec delay significantly depressed running speed in comparison to the performances of the 0 - and 4-sec groups, which were equal to two decimal places. While not significant, the magnitude function virtually parallels the delay function, with the 12-pellet group running the slowest in extinction.

Additional significant interactions were Magnitude by Trials and Delay by Trials $[\mathrm{F}(58,1044)=1.50, \mathrm{p}<.01$ in both cases 1 .

To get at resistance to extinction 
effects in extinction, it is necessary to consider both acquisition and extinction asymptotes. An analysis of asymptotic extinction performance, with each S's asymptote estimated from the last six extinction trials, revealed no significant effects of reward magnitude, delay, or their interaction.

Since there is an acquisition asymptote difference for delay of reward, the data suggest that differences in overall extinction performance for delay are due to differing starting points and not to variations in resistance to extinction. If the main effect for reward magnitude in extinction is considered nominally significant, the opposite situation exists from reward delay. With no magnitude main effect for acquisition asymptote, variation in extinction performance may be attributed to differences in resistance to extinction, with 2 - and 4-pellet reward leading to greater resistance to extinction than 12-pellet reward. DISCUSSION

The present results support predictions from Capaldi's (1966, 1967,1970 ) sequential theory, in part, for both acquisition and extinction. In acquisition, the theory assumes that reward magnitude affects the maximum value of habit strength directly while reward delay affects it inversely. Magnitude is also assumed to interact with habit strength to determine performance through the variable of stimulus intensity.

Reward magnitude did not significantly affect acquisition asymptote here, but, as would be expected from the multiplicative relationship of habit strength and stimulus intensity, it did seem to affect learning rate. This is not a typical finding, but it is in correspondence with the recent results of Ratliff \& Ratliff (1971). Reward delay did significantly affect asymptotic performance level but apparently not learning rate.

Examination of the significant interactions of Magnitude by Delay over all trials and at asymptote indicated that reward magnitude affected asymptotic level of habit strength at longer delays. If a ceiling concept for habit strength such as that of Broen \& Storms (1966) is utilized, both this outcome and the failure to find a main effect for magnitude at asymptote can be explained. If habit strength reached the ceiling at $0-\mathrm{sec}$ delay in every magnitude group, then a magnitude effect could only be observed when delay limited habit strength below that level.

For extinction analysis, sequential theory assumes the existence of stimulus properties unique to various

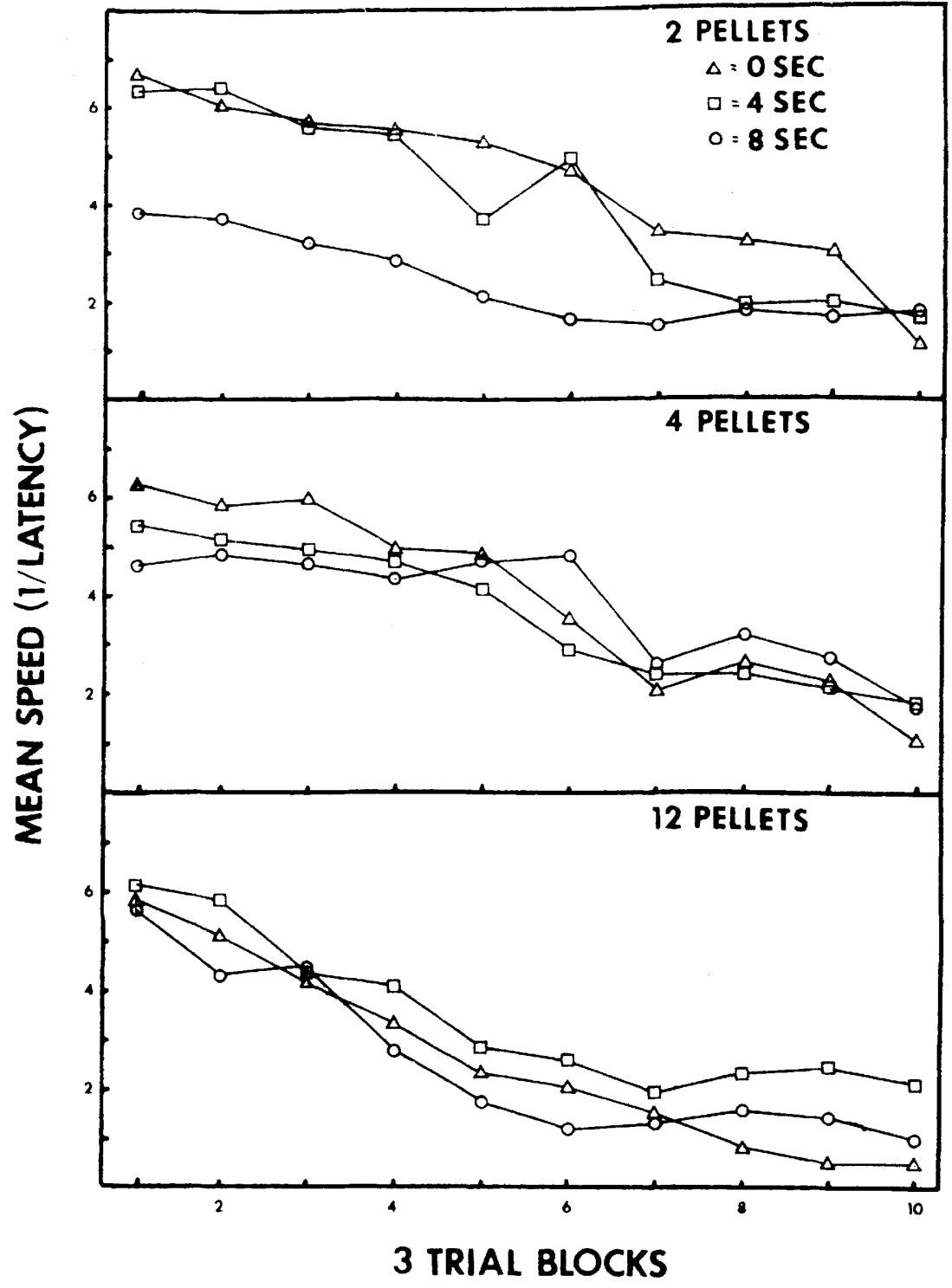

Fig. 2. Mean total running speeds in three-trial blocks for extinction.

magnitude and delay levels. These are available from previous trials for conditioning to the instrumental response, even at 24-h intertrial intervals, if that response is followed by reward (Capaldi, 1970 , pp. 361-367; Robbins, 1971). Resistance to extinction increases as reward gets smaller and delay gets longer because the associated stimuli become more like nonreward at small magnitudes and long delays.

The extinction results are consistent with this sequential analysis, but the nature of the relationship of the stimulus properties of magnitude and delay levels to the magnitude and delay levels of the rewards by which they are conditioned to the instrumental response makes a test of the sequential position difficult in a constant reward and delay situation (Capaldi, 1967; Leonard, 1969). It is clear that effects of the magnitude and delay levels upon extinction should be additive, and the lack of a Magnitude by Delay interaction in extinction in this study does not contradict the theory.

\section{REFERENCES}

BROEN, W. E., JR., \& STORMS, L. H Lawful disorganization: The process underlying a schizophrenic syndrome. Psychological Review, 1966, 73, 265-279.

CAMPBELL, P. E., \& WELLS, J. F., JR. Sequential effects of magnitude of delayed reward and magnitude of immediate reward on pattern running and resistance to extinction. Psychological Record, 1970, 20, 203-210.

CAPALDI, E. J. Partial reinforcement: A hypothesis of sequential effects. 
Psychological Review, 1966, 73, 459-477.

CAPALDI, E. J. A sequential hypothesis of instrumental learning. In $K$. W. Spence and J. T. Spence (Eds.), The psychology of learning and motivation: Advances in research and theory. Vol. 1. New York: Academic Press, 1967. Pp. 67-156.

CAPALDI, E. J. An analysis of the role of reward and reward magnitude in instrumental learning. In J. H. R eynierse (Ed.), Current issues in animal learning. Lincoln: University of Nebraska Press, 1970. Pp. 357-389.

CAPALDI, E. J., GODBOUT, R. C., \& DOWNS, B. Joint effects of magnitude of immediate reward and magnitude of delayed reward on acquisition and extinction. Psychonomic Science, 1968, $13,277-278$.
LEONARD, D. W. Amount and sequence of reward in partial and continuous reinforcement. Journal of Comparative \& Physiological Psychology, 1969, 67, 204-211.

LOGAN, F. A. Incentive, New Haven: Yale University Press, 1960

NUNNALLY, J. C. Psychometric theory. New York: McGraw-Hill, 1967.

PETRINOVICH, L. F., \& HARDYCK, C. D. Error rates for multiple comparison methods: Some evidence concerning the frequency of erroneous conclusions. Psychological Bulletin, 1969, 71, 43-54. RATLIFF, R. G., \& RATLIFF, A. R. Runway acquisition and extinction as a joint function of magnitude of reward and percentage of rewarded acquisition trials. Learning \& Motivation, 1971, 2,
289-295.

ROBBINS, D. Partial reinforcement: A selective review of the alleyway literature since 1960. Psychological Bulletin, 1971 , $76,415-431$.

SGR O, J. A., MOORE, B. D., \& SHOWALTER, J. R. Effect of d-length and magnitude of immediate reward in partial delay. Psychonomic Science, $1970,19,157-158$.

WIST, E. R. Amount, delay, and position of delay of reinforcement as parameters of runway performance. Journal of Experimental Psychology, 1962, 63 160-166 